\title{
Characterization of the dolphinfish (Coryphaenidae) fishery of the United States western north Atlantic Ocean*
}

\author{
NANCY B. THOMPSON \\ Southeast Fisheries Science Center, 75 Virginia Beach Drive, Miami, FL 33149, USA. \\ E-mail: Nancy.Thompson@noaa.gov
}

\begin{abstract}
SUMMARY: Fishery dependent data from various commercial and recreational sampling programs form the basis for characterizing the fishery for dolphinfish (Coryphaenus hippurus) in the waters of the Gulf of Mexico and off the southeastern U.S. coast. Three states in the region have implemented size and bag limits for dolphinfishes, but there are no federal regulations in place at this time. Commercial landings were relatively small in comparison to recreational landings from 1984 through 1996. In 1995 however, commercial landings in the Atlantic Ocean of the southeastern U.S. were almost twice the weight of the previous years. The average weight per fish was calculated for each water body and fishing sector and there appear to have been significant increases in the average weight of fish landed both in the commercial and recreational sectors in the Atlantic and the Gulf of Mexico. Catch per unit of effort is measured as numbers of fish caught per angler per hour in the recreational fishery and has been variable since the early 1980s. In light of increasing landings and average weights of fish landed since the 1980 s, the sustainability of this fishery must be fully evaluated.
\end{abstract}

Key words: Southeast U.S., recreational fishery, commercial fishery, annual landings, annual average weights, length-weight relationship, gear, CPUE.

\section{INTRODUCTION}

Dolphinfish (Coryphaena hippurus) in the Western North Atlantic waters of the United States support both commercial and recreational fishing (Fig.1) The biology of this species, its distributions, stock structure and migratory movements in the Western North Atlantic have been reviewed periodically (Oxenford 1986; Palko et al., unpublished manuscript 1990; Bentivoglio, 1989; Ditty et al., 1994; Palko et al., 1982). Their tendency to form large schools associated with floating objects and

\footnotetext{
*Received March 25, 1998. Accepted March 11, 1999.
}

fixed structures such as oil and gas platforms in the Gulf of Mexico makes them easy targets for fishing (Stanley and Wilson, 1990). There is a significant recreational fishery in the U.S. Atlantic, which exploits their seasonal presence particularly in the summer months in both the Atlantic and Gulf of Mexico (Brusher et al., 1984).

Fishery management for this species in federal waters is under the joint responsibility of the Gulf of Mexico Fishery Management Council and the South Atlantic Fishery Management Council. Recently, concerns have been expressed to the Councils regarding the perceived increase in commercial landings from long lining particularly off the south- 


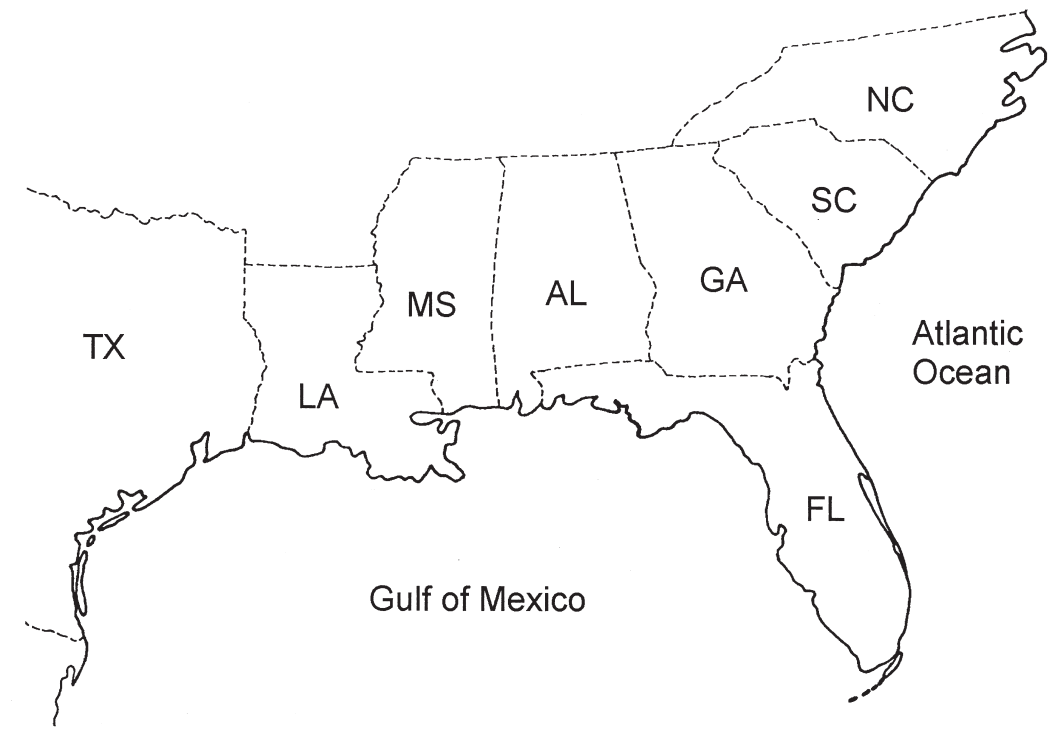

FIG. 1. - Map of the southeastern U.S. coast and the Gulf of Mexico and Atlantic Ocean. The southeast U.S. extends from North Carolina to Texas.

east U.S. coast. Currently within this region there is no management for this species in federal waters and only Florida, North Carolina and Georgia have regulations for their state waters. Florida currently has a 10 fish per person per day limit with a $50.8 \mathrm{~cm}$ fork length size limit for the sale of dolphin. North Carolina also has a limit of 10 fish per person per day for recreational fishery. Georgia has a 15 fish per angler per day limit with a minimum size limit of $45.7 \mathrm{~cm}$ fork length for the recreational fishery. At this time, management alternatives are being considered to insure that catches are sustainable and potential options include trip limits, bag limits, minimum size limits, and gear restrictions.

The purpose of this paper is to describe both the commercial and recreational fishery for dolphinfishes in waters of the southeast United States where this fishery is prosecuted. Catch information is provided for both fishing sectors, commercial and recreational, in the Gulf of Mexico from the Florida west coast to Texas and in southeastern U.S. Atlantic Ocean waters from North Carolina to the Florida east coast. Data are either provided by whole weight of fish or numbers of fish, or both, with samples taken to evaluate weight-length relationships.

Additional information collected includes gear used by the commercial sector and catch per unit of effort for the recreational sector. Catches are presented by area as the Gulf of Mexico and Atlantic Ocean. While it has been suggested that the Western North Atlantic may include multiple stocks (Oxen- ford 1986), the separation of catches by area for this exercise does not imply stock separation and is simply done as a convenient method to track landings for the Regional Fishery Management Councils.

\section{MATERIALS AND METHODS}

\section{Data}

Fisheries dependent data are collected from both the commercial and recreational sectors. Commercial data are reported annually by fish dealers and wholesalers in whole pounds weight and converted to kilograms landed. Individual fish are sampled by port agents under federal or state hire on a trip basis for fork length and weight. A trip is defined as time from leaving the dock to returning to the dock and can be one or several days in length. For the most part, commercial catches are reported as by-catch from fishing that is directed at pelagic species including tunas, swordfish, and sharks.

Fisheries dependent recreational data are from three separate sources which are added to give the figure for total landings. These data are from the National Marine Fisheries Service's (NMFS) Marine Recreational Fisheries Statistical Survey (MRFSS), the state of Texas Recreational Creel Survey, and the NMFS/Southeast Fisheries Science Center (SEFSC) Head Boat Survey. The MRFSS data are collected for the charter, private, and shore 
fishing modes for all states in the southeast U.S. except Texas. Texas data are for all these three modes and include catches from head boats for the state of Texas only. The head boat survey includes all the states except Texas.

Data from the head boat survey are reported by total weight of fish in whole pounds landed per trip. Weights were converted to kilograms and a trip is defined as before as time between leaving and returning to the dock. These trips are generally no more than a single day in length and multiple trips can be completed in one day. The total number of anglers fishing per trip and the length of the trip in total hours are reported. These trip data were used to estimate CPUE as total numbers of fish caught per angler per hour.

The Texas Creel Survey reports numbers of fish landed, total length of each fish landed and weight of each fish in whole pounds. Average weight per fish is multiplied by the total number of fish reported to estimate total pounds in whole weight and is converted to kilogram weight. The total number of anglers and the total hours fished are reported and used to estimate CPUE as number of fish caught per angler per hour.

TABLE 1. - Annual dolphin landings in metric tons. Landings were estimated for the commercial and recreational sectors for Gulf of Mexico and southeastern Atlantic waters.

\begin{tabular}{|c|c|c|c|}
\hline \multicolumn{4}{|c|}{ Atlantic x $1000 \mathrm{~kg}$} \\
\hline Year & Commercial & Recreational & Total \\
\hline 84 & 72.3 & 1556.0 & 1628.3 \\
\hline 85 & 64.9 & 2516.5 & 2581.4 \\
\hline 86 & 86.2 & 3106.8 & 3193.0 \\
\hline 87 & 96.7 & 1999.1 & 2095.8 \\
\hline 88 & 96.5 & 2879.1 & 2975.6 \\
\hline 89 & 193.4 & 4468.3 & 4661.7 \\
\hline 90 & 230.8 & 3377.5 & 3608.3 \\
\hline 91 & 295.6 & 5123.6 & 5419.2 \\
\hline 92 & 148.5 & 2360.4 & 2508.9 \\
\hline 93 & 236.6 & 2461.5 & 2698.1 \\
\hline 94 & 281.2 & 4383.6 & 4664.8 \\
\hline 95 & 529.1 & 5543.1 & 6072.3 \\
\hline 96 & 248.4 & 3379.1 & 3627.5 \\
\hline \multicolumn{4}{|c|}{ Gulf x $1000 \mathrm{~kg}$} \\
\hline Year & Commercial & Recreational & Total \\
\hline 84 & 128.6 & 480.2 & 608.8 \\
\hline 85 & 122.6 & 630.3 & 752.9 \\
\hline 86 & 223.8 & 1394.3 & 1618.1 \\
\hline 87 & 183.6 & 1194.9 & 1378.5 \\
\hline 88 & 226.9 & 534.2 & 761.1 \\
\hline 89 & 502.8 & 1368.3 & 1836.8 \\
\hline 90 & 761.6 & 2341.5 & 2896.8 \\
\hline 91 & 324.9 & 2560.7 & 3322.3 \\
\hline 92 & 271.4 & 1877.2 & 2202.1 \\
\hline 93 & 271.4 & 2369.8 & 2641.2 \\
\hline 94 & 309.1 & 1250.6 & 1559.7 \\
\hline 95 & 535.1 & 3432.3 & 3967.4 \\
\hline 96 & 474.5 & 2148.3 & 2622.7 \\
\hline
\end{tabular}

The MRFSS data are reported as total number of fish caught with samples provided on length and weight of fish to allow for the estimation of total whole pounds landed, which was converted to total kilograms of fish landed. These data were added to the results from the Texas Creel Survey and Head Boat Survey to determine total annual landings by weight in kilograms. The number of anglers and trip length are also reported and used to estimate CPUE as for the other data sets, as number of fish caught per angler per hour. These data, which represent the majority of data for this species, were also sorted and apportioned by mode, as charter, private and shore.

All of the recreational data were pooled to develop a length-weight relationship using the natural log for weight and length and completing a linear regression. This relationship was evaluated for the Atlantic and Gulf of Mexico separately and with the areas combined. This relationship is compared with those available in the literature.

\section{RESULTS}

\section{Landings}

Total landings in metric tons for the Gulf and Mexico and Atlantic for the commercial and recreational fishing sectors are presented in Table 1. The time series for landings begin in 1984 and are considered preliminary for 1996 . Commercial landings were low relative to the recreational sector over the thirteen year time series. While commercial landings in the Gulf of Mexico fluctuated, landings in the Atlantic appear to have increased from 1992 with a peak in 1995 when total landings appear to have nearly doubled as compared to previous years.

Recreational landings fluctuated considerably over this same time period, with a peak in the Atlantic and the Gulf of Mexico in 1995. While the landings from both the Gulf of Mexico and the Atlantic fluctuated over the time series there appears to be an increasing trend in total landings since 1988.

\section{Average weight}

The average weight per fish was evaluated annually for each body of water and fishing sector, with mean value and $95 \%$ confidence intervals from the SE of the mean (Figs. 2-5). The average weight per 


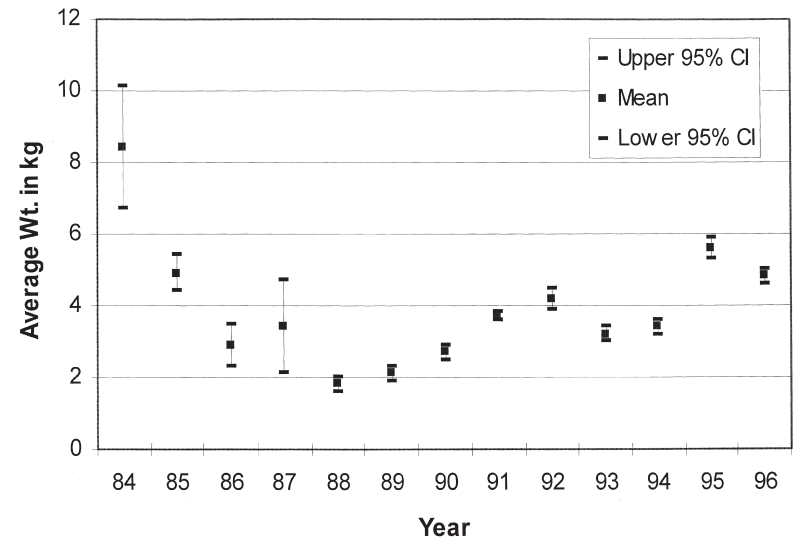

FIG. 2. - Average weight of individual fish by year for the commercial fishery in the Gulf of Mexico. The mean value and 95\% confidence intervals are included.

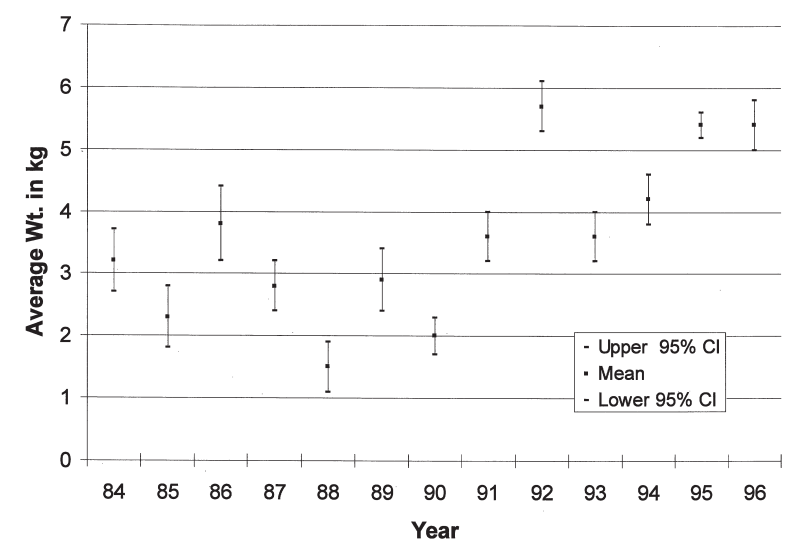

FIG. 3. - Average weight of individual fish by year for the commercial fishery in the southeastern U.S. Atlantic Ocean. The mean value and $95 \%$ confidence intervals are included.

fish increased in the commercial landings in both the Atlantic and Gulf of Mexico (Figs. 2 and 3). In the Atlantic average weight increased from about $1.5 \mathrm{~kg}$ in 1988 to $5.6 \mathrm{~kg}$ in 1996. In the Gulf of Mexico, the increase from 1988 to 1995 was from $1.7 \mathrm{~kg}$ to about $5.6 \mathrm{~kg}$.

The average weight per fish from the recreational sector fluctuated more over the time series begining in 1981, but, there appears to have been an increasing trend in the average weight landed by recreational anglers both in the Atlantic and Gulf of Mexico since the late 1980s (Figs. 4 and 5). Average weight over the time series appears to have almost tripled in the Gulf of Mexico in the recreational sector from about $1.4 \mathrm{~kg}$ per fish to 3.8 $\mathrm{kgs}$ from 1987 to 1996, with significant fluctuations between this time period. In the Atlantic, the magnitude of increase appears to have been from about $2.3 \mathrm{~kg}$ to about $3.0 \mathrm{~kg}$ from 1987 to 1996 , approximately a $25 \%$ increase over this time series.

\section{Length-weight relationship}

The relationship between weight and length was examined using the recreational data because the sample size for both weight and length is large from this sector. Data from each source, MRFSS, Texas Creel Survey, and Head Boat Survey were combined to maximize the sample size available $(\mathrm{N}=32,215)$. The length weight relationship for the Gulf of Mexico and Atlantic were similar when comparing results of log linear regressions, with the intercept and slope not significantly different $(\mathrm{p}<.01)$, and data were pooled over areas with the resulting relationship described as a log linear equation with sample size $(n)$ and $r^{2}$ from the linear regression:

$$
\begin{gathered}
\text { ln weight }=2.71 \ln \text { fl- }-10.42 \\
r^{2}=0.97
\end{gathered}
$$

Where $\ln$ weight=natural $\log$ whole weight in $\mathrm{kg}$ and $\ln \mathrm{fl}=$ natural $\log$ of fork length in $\mathrm{cm}$. In the

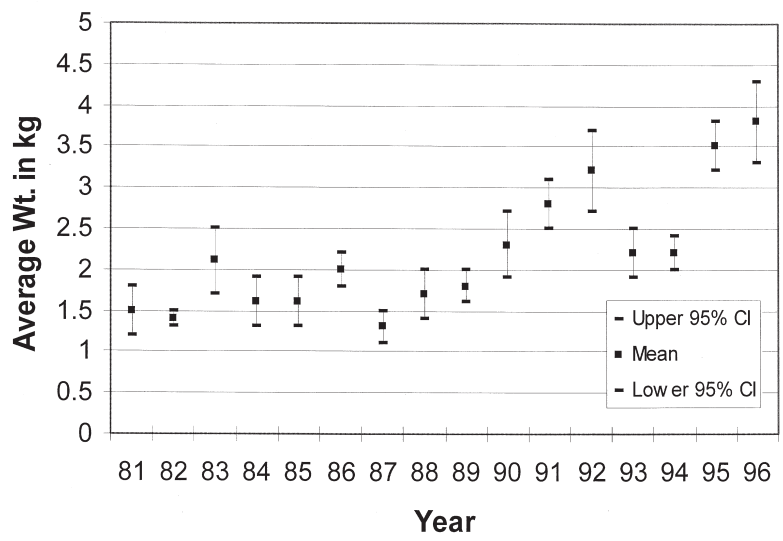

FIG. 4. - Average weight of individual fish sampled from the recreational sector in the Gulf of Mexico. The mean value and 95\% confidence intervals are included.

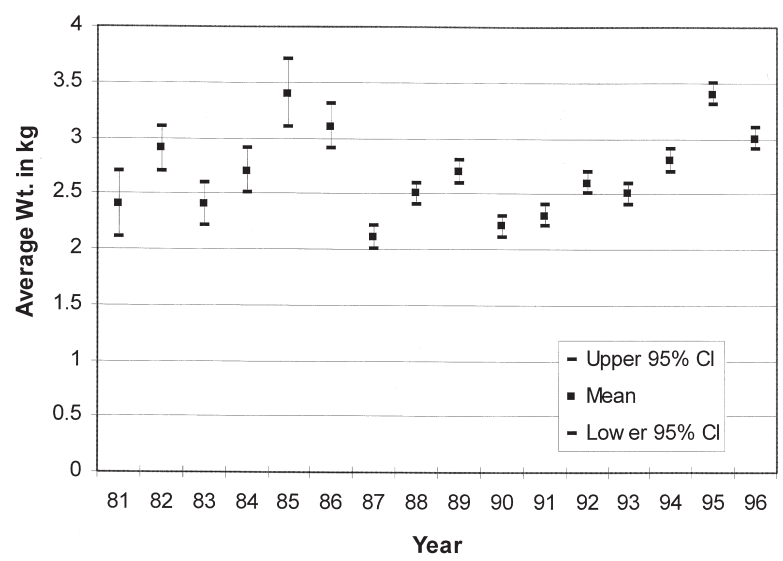

FIG. 5. - Average weight of individual fish sampled from the recreational sector in the southeastern U.S. Atlantic Ocean.The mean value and 95\% confidence intervals are included. 
non-linear form of the equation, this relationship translates to: $\mathrm{A}=2.98 \times 10^{-4} \mathrm{~mm}$ and $\mathrm{b}=2.71$ with $\mathrm{y}=$ weight in kilograms and $\mathrm{x}=$ fork length in $\mathrm{mm}$ where $y=a x^{b}$. This result compares well with the relationship provided by Beardsley (1967), where $\mathrm{A}=2.35 \times 10^{-4}$ and $\mathrm{b}=2.63$ for 40 females sampled from the southeast U.S. Atlantic Ocean. From other published studies it appears that $\mathrm{b}$ ranges from about 2.5 to 3.7 depending on where samples are taken (Palko et al., 1982). The value of b calculated for the 32,000 plus fish sampled throughout the Gulf of Mexico and the Atlantic is within the published range for this parameter.

\section{Gear}

The gear types reported for the commercial landings included troll lines, rod and reel which includes both manual and electric, and long lines which includes surface lines and traditional swordfish type long lines. The distribution of records for the commercial sector was: 6977 or $54.3 \%$ from trolling lines; 4845 or $37.7 \%$ from rod and reel; 1003 or $7.9 \%$ from long lines; and 16 or $0.1 \%$ from unknown gear.

The gear from the recreational sector was almost always noted as hook and line and taken primarily from the shore, charter boat and private or rental boat. A charter boat is a vessel for hire that usually includes a captain, one crew member and usually no more than 6 anglers per trip. Of a total of 32,906 records from the MRFSS, 32,898 or nearly all records reported landing dolphinfish by hook and line. For the Gulf of Mexico, 65.3\% (2,250) of the total reports $(n=3,513)$ were from the charter boat mode. A total of 1,218 or $34.7 \%$ of the reports were from the private/rental mode. Less than $1 \%$ were reported as landed while fishing from the shore.

\section{Catch per unit of effort}

Catch per unit of effort was estimated from the three recreational data bases as the total number of fish caught per angler per hour (Figs. 6 and 7). These CPUE indices can be compared between sampling programs, water bodies and years. CPUE for the Gulf of Mexico was estimated from the Texas Creel Survey, the Head Boat Survey, and the MRFSS (Fig. 6). The total catches from the head boat survey are small, as would be expected given that these trips are generally prosecuted nearshore and not in deeper shelf waters where dolphinfish are

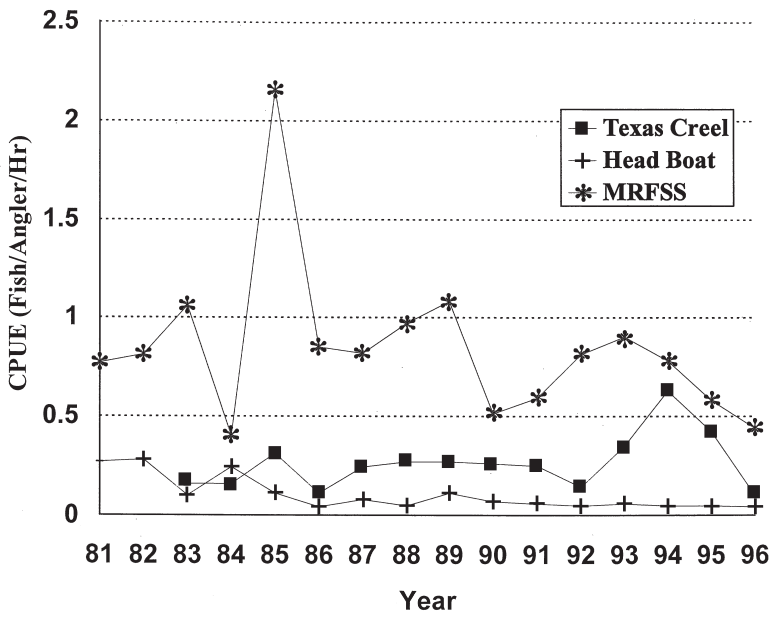

FIG. 6. - Annual number of fish reported by each angler per hour of fishing (CPUE) for the Gulf of Mexico recreational fishery. The three data sources for recreational samples are the Texas creel survey (Texas); the head boat survey (Head boat); and the Marine RecreationalFishery Statistical Survey (MRFSS).

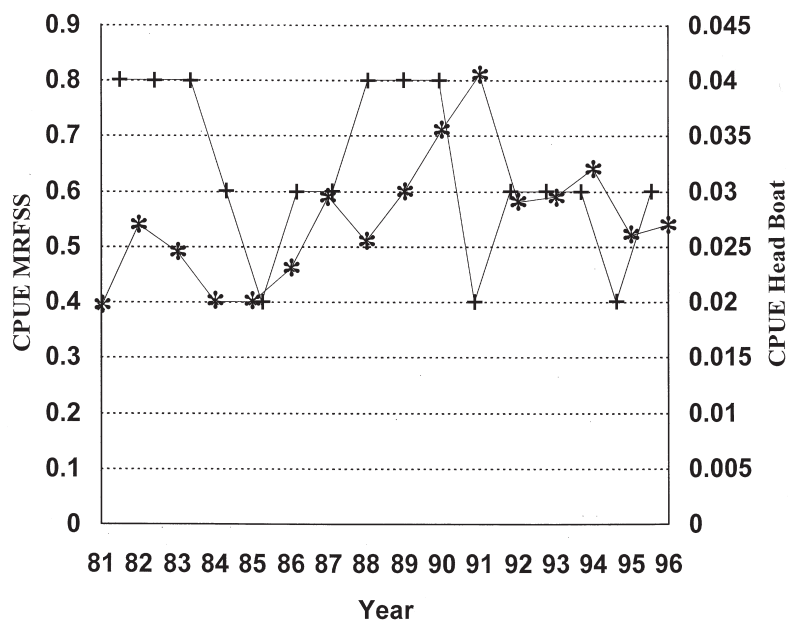

FIG. 7. - Annual number of fish reported per angler per hour of fishing (CPUE) for the southeastern U.S. Atlantic Ocean. The sources of samples were from the head boat survey (Head boat -+-), and the Marine Recreational Fishery Statistical Survey (MRFSS - *-).

more common. The Texas Creel Survey data are also consistently low except from 1993 to 1995 when a significant peak in CPUE occurred. Note that the 1996 data are preliminary only and incomplete. Estimated CPUE from the MRFSS is higher, as was expected since the charter boat fishery is a large component of the catch, with generally more than a single angler on board and they most likely are targeting pelagic species including dolphin. Since dolphin tend to aggregate at certain size classes, they are easily caught in large numbers by several anglers. In addition, in federal waters there is no limit to the numbers which can be landed, and even in Florida state waters the bag limit is currently 10. 
CPUE from the MRFSS fluctuates almost annually, suggesting that this species may in fact be an annual crop.

Estimated CPUE for the southeastern U.S. Atlantic Ocean included the MRFSS and Head Boat Survey only, since Texas is limited to the Gulf of Mexico (Fig. 7). CPUE for the head boat fishery has fluctuated without trend over the past 16 years. CPUE for the MRFSS appears to have increased from 1986 to 1990 and been somewhat stable and comparatively high since 1991. The CPUE estimate for 1996 is preliminary as the data are incomplete for this year.

\section{DISCUSSION}

Dolphinfish support both commercial and recreational fishing throughout the waters of the U.S. Western North Atlantic. The fishery for dolphinfishes remains dominated by the recreational sector, with the highest amount of landings reported from the Atlantic Ocean from Florida to North Carolina. There appears to be an increasing trend in landings in this fishery in both sectors and in both areas.

The average weight of fish landed has been increasing since 1981 in the recreational sector in the Gulf of Mexico, where the average weight more than doubled from about $1.2 \mathrm{~kg}$ in 1987 to almost 4 $\mathrm{kg}$ in 1996. In the Atlantic Ocean the average weight of fish landed recreationally has been variable annually but largely stable and between $2.5 \mathrm{~kg}$ to $3.5 \mathrm{~kg}$. In the commercial sector, the average weight of fish landed has been variable but increasing since 1984 in the Atlantic Ocean. The lowest average weight of about $1.5 \mathrm{~kg}$ was estimated in 1988 and the highest weight of over $5.5 \mathrm{~kg}$ in 1992. In the Gulf of Mexico a similar trend of variable and increasing average weight also appears, with a low of about $2 \mathrm{~kg}$ in 1988 and the highest average weight of almost $6 \mathrm{~kg}$ in 1995 .

While both landings and average weight of fish appear to be increasing since the early or mid-1980s, CPUE is highly variable and an overall trend is not obvious. There is significant variability in CPUE in the Atlantic Ocean, while CPUE in the Gulf of Mexico may be decreasing over this time series.

The trends of increasing landings and average weight suggests that there may be a shift in selection of larger fish by recreational and commercial fishers. Recreational effort is clearly directed seasonally at dolphin and now appears to be directed at larger fish than in the early 1980s. A possible shift in the commercial effort towards larger fish may be a result of changes in effort towards the target species (billfish, tuna, sharks) or may be a result of directing effort towards dolphinfish. There are likely to be other hypotheses to explain these trends.

Sample sizes to describe shifts in gear in the commercial sector are small when stratified annually, but in sum the dominant gear types have been trolling gear and rod and reels, including both manual and electric. For the recreational sector, the overwhelming majority of fish are reported as caught by hook and line, with the charter boat and private/rental boat modes dominating the catches.

It is difficult to evaluate the sustainability of the fishery based on these trends and in the context of such large annual variability in the catches. However, the increases in landings and average weight of fish landed with stable and perhaps decreasing CPUE in the recreational sector suggest that this must be evaluated to determine whether a significant shift or change in the prosecution of this fishery has occurred. In this way, the status of this species and condition of the fishery can be measured to insure sustainability.

\section{ACKNOWLEDGEMENTS}

The data used in this manuscript were obtained through the efforts of various programs and people, including the field samplers for the Southeast Fisheries Science Center (SEFSC) and the individual states. The actual data sets I used in manipulating these data were assembled by Ms. Patty Phares, Division of Sustainable Fisheries (DSF), SEFSC, Miami, Florida. Similar compilations of landings were completed by Mr. Josh Bennett, DSF, SEFSC, Miami, Florida and used to verify the data included in this paper. I gratefully acknowledge these people and their efforts in forming the basis for this manuscript. Two anonymous reviewers provided guidance and helpful advice which I followed as much as possible and hopefully resulted in an improved presentation and overall paper based on my interpretation of their suggestions.

\section{REFERENCES}

Beardsley, G.L. Jr. - 1967. Age, growth, and reproduction of the dolphin, Coryphaena hippurus, in the Straits of Florida. Copeia 1967 (2): 441-451.

Bentivoglio, A.A. - 1989. Investigations in the growth, maturity, 
mortality rates and occurrence of the dolphin (Coryphaena hippurus, Linnaeus) in the Gulf of Mexico. Ph.D. thesis, Univ. College of North Wales.

Brusher, H.A., M.L. Williams, L. Trent and B.J. Palko. - 1984 Using charter boat catch records for Fisheries Management. Mar. Fish. Rev., 46 (3): 48-56.

Ditty, J.G., R.F. Shaw, C.B. Grimes and J.S. Cope. - 1994. Larval development, distribution, and abundance of common dolphin, Coryphaena hippurus, and pompano dolphin, C. equiselis (Family: Coryphaenidae), in the northern Gulf of Mexico. Fish Bull. U.S., 92: 275-291.
Oxenford, H.A. - 1986. A preliminary investigation of the stock of the dolphin, Coryphaena hippurus, in the western central Atlantic. Fish. Bull. U.S., 84: 451-459.

Palko, B.J., G.L. Beardsley and W.J. Richards. - 1982. Sypnopsis of biological data on dolphin-fishes, Coryphaena hippurus Linnaeus and Coryphaena equiselis Linnaeus. NOAA Tech. Rpt. NMFS Circular 443, 28 pp.

Stanley, D.R. and C.A. Wilson. - 1990. A fishery-dependent based study of fish species composition and associated catch rates around oil and gas structures off Louisiana. Fish.Bull. 88: 719730 , 